\title{
Relationships between tree sparrow PasserPasser montanus fledging success and the quantity and quality of agricultural habitats - a model comparison study
}

by McHugh, N.M., Prior, M., Leather, S.R. and Holland, J.M.

Copyright, Publisher and Additional Information: This is the author accepted manuscript. The final published version (version of record) is available online via Elsevier

Please refer to any applicable terms of use of the publisher.

DOI: https://doi.org/10.1016/i.ecoinf.2017.07.002

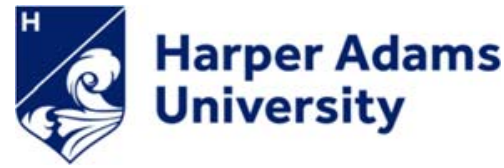

McHugh, N.M., Prior, M., Leather, S.R. and Holland, J.M. 2017. Relationships between tree sparrow PasserPasser montanus fledging success and the quantity and quality of agricultural habitats - $\mathrm{A}$ model comparison study. Ecological Informatics. 
1 Relationships between Tree Sparrow Passer montanus fledging success and the quantity and quality of agricultural habitats - a model comparison study.

Niamh McHugh 1,2, Matt Prior ${ }^{3}$, Simon R. Leather', John M. Holland ${ }^{2}$

${ }^{1}$ Silwood Park Campus, Imperial College London, Buckhurst Road, Ascot, Berkshire, 6 SL5 7PY, UK; ${ }^{2}$ Game and Wildlife Conservation Trust, Fordingbridge, Hampshire, SP6 IEF,

7 UK, ${ }^{3}$ Wiltshire Ornithology Society, 1 Rother Close, Greenmeadow, Swindon, Wiltshire,

8 SN25 3PZ, UK; ${ }^{4}$ Crop and Environment Sciences, Harper Adams University, Newport, TF10

$98 N B, U K$

\section{Abstract}

Changes in land use due to agricultural intensification are a key anthropogenic cause of biodiversity declines impacting invertebrate, plant and bird populations. This study assesses whether fledging success in the tree sparrow, a farmland bird that has declined by over $94 \%$ since 1970, is best described by patterns of agricultural habitat coverage or by the quality (measured by invertebrate chick food abundance) of these habitat patches. We were particularly interested in the effect of agri-environment scheme (AES) habitats on reproductive success, as AES include habitat prescriptions that are employed to alleviate biodiversity problems. Our results indicated that the habitat coverage model best fitted the fledging success data and estimates from this model show that fledging success decreased with the area of wild bird seed mix and grassland cover within the average adult foraging range. Habitat coverage models are currently the most popular method of investigating AES bird relationships and our findings provide support to such studies. These models could be used to assess whether AES farmland bird conservation strategies are successfully improving reproductive success.

\section{Introduction}

To study the way in which habitat change may be influencing a species' decline, it is usually necessary to make an assessment of habitat quality. Many studies that seek to do this rely on simple measures of habitat quality based on the extent, or abundance, of certain habitat features rather than a measure based upon qualitative traits, such as the resources the habitat provides. Using more representative measures of habitat quality should increase the effectiveness of conservation strategies derived from such studies. 
Agricultural intensification is considered responsible for widespread biodiversity losses, amongst a variety of taxa including invertebrates e.g. marsh fritillary Euphydryas aurinia and small blue Cupido minimus butterflies (Fox et al., 2015), along with parallel declines in bird species associated with farmland e.g. cirl bunting Emberiza cirlus and Eurasian stone curlew Burhinus oedicnemus (Peach et al., 2001; MacDonald et al 2012). Agri-environment schemes (AES) are designed to mitigate against such losses and are targeted so that landowners can undertake management relevant to local environmental priorities (Natural England 2013a; 2013b).

Many studies of AES use substrate composition variables as a measure of habitat quality, but do not assess whether the intended resources are being provided (e.g. Baker et al., 2012; Bradbury and Allen, 2003; Bright et al., 2015; McHugh et al., 2016a). Alternatively, studies take simple measures of resource provision (e.g food abundance, prey and predator visibility; Atkinson et al., 2004; 2005) but rarely weight habitats based on these measurements (but see Ponce et al., 2014). It is possible, however, that the relationship between a species and their habitat is best described by combined habitat extent - resource measurements i.e. in terms of functional space (Butler and Norris., 2013). In the context of AES, monitoring habitat quality effectively and appropriately is particularly important, due to the huge financial investment made across the European Union (€34.5bn for 2007 - 2013; IEEP, 2008). For farmland birds it is essential to ensure that once AES habitats are in place birds are receiving the benefits, such as cover from predators, accessible prey and abundant food, that the habitats are designed to provide.

The main aim of this study was to investigate how Eurasian tree sparrow Passer montanus (hereafter tree sparrow) fledgling success, a measure of reproductive success, responds to both simple habitat models and those that are weighted by a measure of resource provision, in this instance in terms of food availability. The predictive power of models were compared using an information theory approach and to our knowledge it is the first example of a study that compares reproductive success models based on simple habitat measurements to those describing functional space.

\section{Methods}

\subsection{Study Sites}


Fieldwork was conducted across the Marlborough and Pewsley Downs, Wiltshire, UK. Nest box monitoring took place on 11 farms and within these farms, groups of nestboxes were defined as breeding colonies when separated from the nearest alternative group of next boxes by 400 or more meters $(n=23)$. The habitats available to tree sparrows inhabiting nest boxes were grouped into 5 categories representing structurally similar feeding habitats; winter cereals (winter wheat, winter barley), grassland (permanent and temporary grassland), oilseed rape, grass AES (2m, 4m and $6 \mathrm{~m}$ arable grass margins, wildflower margins, pollen and nectar margins, grass field corners) and wild bird seed mixture (WBSM).

Habitats were mapped using ArcGIS version 10.2.1 (ESRI, 2015) to calculate the surface area of land used within $80 \mathrm{~m}$ of occupied nest boxes. We choose to map habitat within $80 \mathrm{~m}$ 's of nestboxes as adult tree sparrows are known to collect food for their chicks between 20 and $200 \mathrm{~m}$ from their nests (Deckert, 1962), but their average foraging distance is $80 \mathrm{~m}$ (SummersSmith, 1995).

\subsection{Food availability}

During July 2013, two sweep samples were taken from winter wheat, winter barley, permanent and temporary grassland, oilseed rape, $2 \mathrm{~m}, 4 \mathrm{~m}$ and $6 \mathrm{~m}$ arable grass margins, wildflower margins, pollen and nectar margins, grass field corners and wild bird seed mixture habitats when present within the foraging range of a tree sparrow colony (table 1). Where more than one replicate of these habitats was available to a colony the replicate to be sampled was randomly chosen using R. Random points within these habitats were chosen as sampling locations using ArcGIS v10.2.1.

Sweep netting was used to take invertebrate samples as it is quick and samples are easy to process. Samples comprised ten 180 degree sweeps, covering a distance of approximately $10 \mathrm{~m}$ and a width of $2 \mathrm{~m}$. There are however, some limitations relating to this method including the variance in sampling efficiency relating to habitat type sampled and variation in the species recorded depending on their vertical distribution (Southwood, 1987).

Invertebrate abundance was also estimated for each habitat type using Vortis (Burkard Manufacturing Co. Ltd.) suction samples, using samples that were collected from three farms as part of a separate study (table 1; McHugh et al., 2016a). The Vortis Suction Sampler (Burkard Manufacturing Co. Ltd.) has a suction area of approximately $0.08 \mathrm{~m}^{2}$. Three samples 
were taken from each component habitat at $20 \mathrm{~m}$ intervals this sampling regime was chosen due to a combination of time and weather constraints. Each of these three samples was made up of 5 sucks lasting 25 seconds each, the nozzle pressed to the ground and samples therefore covered a total area of $0.4 \mathrm{~m}^{2}$.

Both sweep net and Vortis suction samples were stored in plastic bags for freezing before being sorted for identification. Debris was removed from samples before storing them in $70 \%$ alcohol. All tree sparrow chick-food invertebrates $>2 \mathrm{~mm}$ long were identified, namely the sum of Araneae, Carabidae, other adult Coleoptera, coleopteran larvae, Diptera, Lepidoptera larvae and Tipulidae (McHugh et al., 2016b); smaller individuals were not identified as they do not constitute an important part of farmland bird diet (Westbury et al., 2011).

Habitat extent data (extracted from ArcGIS) was weighted by calculating the abundance of invertebrates collected via suction sampling and sweep netting abundance per $\mathrm{m}^{2}$ and multiplying this by the total area of each habitat category.

\subsection{Bird Data}

Data on tree sparrow fledging success was recorded during the summers of 2013 and 2014. Nest boxes were monitored every 2-3 days and for each brood we recorded both the number of chicks which fledged successfully and the number that did not.

\subsection{Generalized Linear Mixed-effects Model (GLMM)}

Statistical analysis were conducted in R, v3.2 (R Core Development Team, 2015). In order to determine whether fledgling success could be best explained by simple habitat area measurements or by a measure of invertebrate food abundance we used a series of generalized linear mixed effects models (GLMM) with binomial error distributions. The LME4 package was used to build GLMMs with the GLMER function (Bates et al., 2015). An information theory approach was taken to identify the optimal model that describes tree sparrow fledging success (Burnham and Anderson, 2002). When using this method a series of models are specified and are compared based on AIC weights. Four models were compared a 1) null model, 2) habitat extent model, 3) habitat extent weighted by sweep net invertebrates and 4) habitat extent weighted by Vortis invertebrates. Each model contained the nested random effects structures Farm/Colony/Year and Nest Box ID/Brood. 
136

\section{Results}

137 Our habitat extent model revealed a significant negative relationship between fledging success and the surface area of WBSM and grassland habitats (table 2). In contrast, neither the sweep-net or Vortis weighted functional space models revealed significant habitat - bird

140 relationships (table 3 ).

Model comparison via an information theory approach revealed that tree sparrow fledging success could be best explained by our habitat extent model, which had the highest Akaike weight, valued at 0.751 . This was followed by the null model which received a weighted value of 0.103 . The sweep net weighted and Vortis weighted food models were least successful at explaining the relationship between fledgling success and the environment with values of 0.079 and 0.067 respectively. An Akaike weight of 1 signifies that a model is supported unequivocally over the other candidates. Consequently, this indicates that if sampling was increased or repeated, then in $75.1 \%$ of the instances the habitat extent model is the best model, in $10.3 \%$ of cases models the null model is the best model, in $7.9 \%$ of cases the sweep net weighted model is best and in $6.7 \%$ of cases the Vortis weighted models is best.

\section{Discussion}

Habitat models explained the relationship between tree sparrow fledgling success and the environment more effectively than those that incorporated measures of food availability. Differences in the explanatory power of these models highlight the importance of a model comparison approach when assessing habitat quality.

Ponce et al. (2014) compared the predictive power of habitat and food models during three bird life stages; breeding, post-fledging and over-wintering. They found that models of bird species-richness, diversity and total abundance during post-fledgling and over-wintering periods were improved by between $13 \%$ and $20 \%$ by including measures of invertebrate and seed abundance. Like our study, they report that during the breeding season, food weighted models were no better than habitat extent models in predicting responses in the bird community. In their study they highlight the importance of investigating food and habitat models at different points in the annual cycle, however, they do not consider how bird responses may differ throughout a bird's life cycle. Our result shows that when studying 
multiple ecological constraints that limit the use of resources e.g. predation pressure, intensity of competition, and physical accessibility of prey. Additionally, Ponce et al.'s 2014 study was based on analysis of whole bird community responses, but the effectiveness of food and habitat models may differ between individual species depending on their foraging strategies.

Our finding that the habitat model best fitted the fledging success data was unexpected and there are a number of potential alternative explanations for this result. Firstly, habitat sampling may have taken place on too small a scale and may not be representative of the landscape; more information may have been revealed by increasing our sampling effort. Alternatively, the invertebrate sampling methods used may not have appropriately captured the invertebrate diversity within these habitats or do not accurately represent the foraging behaviour of tree sparrows. Our result may also relate to the timing of invertebrate sampling. Invertebrate samples were taken in late summer; at this time some invertebrates (e.g. Carabidae and Staphylinidae) will have migrated from overwinter refuges in boundaries into crops (Thomas et al., 2001) and aphid populations will have crashed (Karley et al., 2004). Douglas et al., (2009) support this theory and report that the difference in chick food abundance between crop and grass margins was lowest in July. Chick food will still be in peak demand at this time for a number of vulnerable farmland species including the tree sparrow (Ferguson-Lees et al., 2011). If this study were to be repeated, we would recommend collecting more detailed information on seasonal patterns of food availability as this would result in more accurately weighted models.

Habitat coverage models are currently the most popular means of investigating the potential benefits of AES to birds (e.g. Baker et al., 2012; Bradbury and Allen, 2003; Bright et al., 2015; Davey et al., 2010; Henderson et al., 2012) and although our findings provide some support to this method, we recommend that future studies comparing the explanatory power of food and habitat extent models do so for a variety of species. This will ensure that habitat extent models appropriately describe bird-habitat relationships for different functional groups (granivorous, insectivorous etc; Henderson et al., 2000) and that these models also focus on different stages in a bird's life cycle (e.g. fledgling, post-fledgling). Future studies could also include measures of other ecological constraints, for example vegetation density could be used as a measure of resource accessibility and cover from predators. Additionally, the spatial arrangement of AES habitats could be considered as habitat configuration may be critical for central place foragers such as tree sparrow due to their limited foraging range. This 
information may be needed to help interpret the responses of bird species to AES interventions and consequently allow more representative evaluations of AES's efficiency.

\section{Acknowledgement}

We thank C.J. Heward for comments on earlier draft of the manuscript and the landowners who allowed us access to their land throughout the project.

\section{Funding Information}

This project was financed through a BBSRC case studentship with the Game and Wildlife Conservation Trust [grant number BB/F017324/1], with additional funding provided by Natural England's Evidence Programme.

\section{References}

Atkinson, P.W., Buckingham, D., Morris, A.J., 2004. What factors determine where invertebrate-feeding birds forage in dry agricultural grasslands? Ibis 146, 99-107.

Atkinson, P.W., Fuller, R.J., Vickery, J.A., Conway, G.J., Tallowin, J.R.B., Smith, R.E.N., Haysom, K.A., Ings, T.C., Asteraki, E.J., Brown, V.K., 2005. Influence of agricultural management, sward structure and food resources on grassland field use by birds in lowland England. J. Appl. Ecol. 42,932-942.

Baker, D.J., Freeman, S.N., Grice, P. V., Siriwardena, G.M., 2012. Landscape-scale responses of birds to agri-environment management: a test of the English Environmental Stewardship scheme. J. Appl. Ecol. 49, 871-882

Bates D., Maechler M., Bolker B., Walker S., 2015. lme4: Linear mixed-effects models using Eigen and S4. R package version 1.1-9, URL: https://CRAN.R-project.org/package=lme4

Bradbury, R.B., Allen, D.S., 2003. Evaluation of the impact of the pilot UK Arable Stewardship Scheme on breeding and wintering birds: Few positive responses by birds were observed in the first two years of this new agri-environment scheme. Bird Study 50, 131-141.

Bright, J.A., Moris, A.J., Field, R.H., Cooke, A.I., Grive, P.V., Walker, L.K., Fern, J., Peach, W.J., 2015. Higher-tier agri-environmnet scheme enhances breeding densities of some priority farmland birds in England. Agric. Ecosyst. Environ. 203, 69-79.

Burnham, K.P., Anderson, D.R., 2002. Model Selection and Multimodel Inference: A Practical Information-Theoretic Approach. Springer-Verlag, 2nd edn.

Butler, S.J., Norris, K., 2013. Functional space and the population dynamics of birds in agro-ecosystems. Agric. Ecosyst. Environ. 164,200-208. 

lowland farmland birds in England. Ibis 152, 459-474.

Deckert, G., 1962. Zur Ethologie des Feldsperlings (Passer montanus L.). J. Ornithol. 103, 428-486.

Douglas, D.J.T., Vickery, J.A. \& Benton, T.G., 2009. Improving the value of field margins as foraging habitat for farmland birds. J. Appl. Ecol. 46, $353-362$.

ESRI (Environmental Systems Resource Institute), 2015. ArcMap 10.2.1. ESRI, Redlands, California.

Fergusen-Lees, J., Castell, R., Leech, D., 2011. A Field-guide to Monitoring Nests. BTO., Tring, UK.

Fox, R., Brereton, T.M., Asher, J., August, T.A., Botham, M.S., Bourn, N.A.D., Cruickshanks, K.L., Bulman, C.R., Ellis, S., Harrower, C.A., Middlebrook, I., Noble, D.G., 268 Powney, G.D., Randle, Z., Warren, M.S., Roy, D.B., 2015. The State of the UK's Butterflies 2015. Butterfly Conservation and the Centre for Ecology \& Hydrology, Wareham, Dorset.

Henderson, I. G., Cooper, J., Fuller, R.J., Vickery, J. 2000. The relative abundance of birds on set-aside and neighbouring fields in summer. J. Appl. Ecol. 37:335-347.

Henderson, I.G., Holland, J.M., Storkey, J., Lutman, P., Orson, J., Simper, J., 2012.

Effects of the proportion and spatial arrangement of un-cropped land on breeding bird abundance in arable rotations. J. Appl. Ecol. 49, 883-891.

IEEP 2008. Funding for farmland biodiversity in the EU: Gaining evidence for the EU budget review. A report for the RSPB.

Karley, A. J., Parker, W. E., Pitchford, J. W., Douglas, A. E., 2004. The mid-season crash in aphid populations: why and how does it occur? Ecol. Entomol. 29(4), 383-388.

Summers-Smith, J.D. (1995) The Tree Sparrow. J.D. Summers-Smith, Guisborough.

MacDonald, M.A., Maniakowski, M., Cobbold, G., Grice, P. V., Anderson, G.Q.A., 2012. Effects of agri-environment management for stone curlews on other biodiversity. Biol. Conserv. 148, 134-145.

McHugh, N. M., Goodwin, C. E., Hughes, S., Leather, S. R., Holland, J. M., 2016a. AgriEnvironment Scheme Habitat Preferences of Yellowhammer Emberiza citrinella on English Farmland. Acta Ornithol. 51(2), 199-209

McHugh, N. M., Prior, M., Leather, S. R., Holland, J. M., 2016b. The diet of Eurasian Tree Sparrow Passer montanus nestlings in relation to agri-environment scheme habitats. Bird 
Natural England. 2013a. Environmental Stewardship Handbook. Entry Level Stewardship. Fourth Edition. Natural England Report.

Natural England. 2013b. Environmental Stewardship Handbook. Higher Level Stewardship. Fourth Edition. Natural England Report.

Peach, W.J., Lovett, L.J., Wotton, S.R., Jeffs, C., 2001. Countryside stewardship delivers cirl buntings (Emberiza cirlus) in Devon, UK. Biological Conservation 101, 361-373.

Ponce, C., Bravo, C., Alonso, J.C., 2014. Effects of agri-environmental schemes on farmland birds: do food availability measurements improve patterns obtained from simple habitat models? Ecol. Evolut. 4 (14) p. 2834-47

R Core Development Team. 2015. R version 3.0.2: A Language and Environment for Statistical Computing. Austria: R Foundation for Statistical Computing. URL http://www.Rproject.org/.

Southwood, R. 1987. Ecological methods: With particular reference to the study of insect populations. Springer.

Thomas, S.R., Goulson, D., Holland, J.M. 2001. Resource provision for farmland gamebirds: the value of beetle banks. Ann. Appl. Biol. 139, 111-118.

Westbury, D.B., Mortimer, S.R., Brook, A.J., Harris, S.J., Kessock-Philip, R., Edwards, A.R., Chaney, K., Lewis, P., Dodd, S., Buckingham, D.L., Peach, W.J., 2011. Plant and invertebrate resources for farmland birds in pastoral 
Table 1. The total number of samples taken from each habitat type is outlined with the number of farms these samples represent displayed in brackets.

\begin{tabular}{lll}
\hline Habitat Type & Sweep Net & Vortis \\
\hline Winter Cereal & $44(9)$ & $12(3)$ \\
Pasture & $31(10)$ & $9(3)$ \\
Oilseed rape & $20(5)$ & $9(3)$ \\
Grass AES & $49(8)$ & $18(3)$ \\
WBSM & $15(5)$ & $6(2)$ \\
\hline
\end{tabular}

Table 2. Results of GLMM models under investigation.

\begin{tabular}{llllll}
\hline & Covariate & Estimate & Std. Error & Z value & P \\
\hline Null model & Intercept & 0.849 & 0.197 & 4.318 & $<\mathbf{0 . 0 0 1}$ \\
\hline Habitat model & Intercept & 1.661 & 0.545 & 3.049 & $<\mathbf{0 . 0 1}$ \\
& Grass AES & 0.695 & 1.597 & 0.435 & 0.664 \\
& OSR & 0.276 & 0.447 & 0.617 & 0.537 \\
& WBSM & -2.289 & 1.149 & -1.922 & $<\mathbf{0 . 0 5}$ \\
& Grassland & -1.503 & 0.676 & -2.225 & $<\mathbf{0 . 0 5}$ \\
& Winter Cereal & -0.763 & 0.490 & -1.557 & 0.120 \\
\hline Food model & Intercept & 1.579 & 0.559 & 2.825 & $<\mathbf{0 . 0 1}$ \\
(sweep) & Grass AES & 0.005 & 0.055 & 0.100 & 0.921 \\
& OSR & 0.029 & 0.036 & 0.804 & 0.422 \\
& WBSM & -0.101 & 0.064 & -1.572 & 0.116 \\
& Grassland & -0.074 & 0.055 & -1.355 & 0.175 \\
Food model & Winter Cereal & -0.082 & 0.046 & -1.775 & 0.075 \\
(Vortis) & Intercept & 1.618 & 0.560 & 2.889 & $<\mathbf{0 . 0 1}$ \\
& Grass AES & 0.001 & 0.039 & 0.021 & 0.983 \\
& OSR & 0.019 & 0.027 & 0.719 & 0.472 \\
& WBSM & -0.064 & 0.044 & -1.447 & 0.148 \\
& Grassland & -0.051 & 0.038 & -1.347 & 0.178 \\
& Winter Cereal & -0.055 & 0.028 & -1.940 & 0.052 \\
\hline
\end{tabular}

Table 3. Comparison of alternative models with details of the degrees of freedom (DF), AIC values, differences in AIC values and Akaike weights for all models.

\begin{tabular}{lllll}
\hline Model & DF & AIC & AIC differences & Akaike weights \\
\hline Null & 6 & 1507.120 & 3.968 & 0.103 \\
Habitat & 11 & 1503.152 & 0.000 & 0.751 \\
Food (sweep) & 11 & 1507.652 & 4.500 & 0.079 \\
Food (vortis) & 11 & 1507.985 & 4.833 & 0.067 \\
\hline
\end{tabular}

